УДК 630*311:004.4

ИССЛЕДОВАНИЕ ЗАВИСИМОСТИ СКОРОСТИ ДВИЖЕНИЯ АВТОЛЕСОВОЗОВ ОТ ПРИРОДНО-КЛИМАТИЧЕСКИХ ФАКТОРОВ

${ }^{1}$ Мохирев А.П., ${ }^{2}$ Рукомойников К.П., ${ }^{1}$ Герасимова М.М., ${ }^{1}$ Медведев С.О.

${ }^{1}$ Сибирский государственный университет науки и технологий им. М.Ф. Решетнева филиал в г. Лесосибирск, Лесосибирск, e-mail: ale-mokhirev@yandex.ru;

${ }^{2}$ Поволжский государственный технологический университет, Йошкар-Ола, e-mail: rukomojnikovkp@volgatech.net

Доступность лесных ресурсов является важнейшим фактором развития лесозаготовительной инфраструктуры. При ее определении рассчитывается максимально возможный объем вывозки древесины, зависящий от пропускной способности транспортных путей, на которую влияет множество производственных и природно-климатических факторов. Одним из параметров, позволяющих прогнозировать пропускную способность лесных дорог, является скорость движения автолесовоза. Она может выступать индикатором состояния дороги и использоваться в качестве критерия оптимальности при оптимизации лесотранспортных процессов при освоении лесных массивов. Данная статья посвящена исследованию зависимости этого показателя от природноклиматических факторов при движении на различных категориях лесовозных дорог (магистраль, ветка, ус) в различное время года. Объектом исследования являются автомобильные лесовозные дороги, находящиеся в интенсивно используемых лесозаготовительных районах Красноярского края. Для получения регрессионных уравнений выполнено планирование эксперимента. Найдены регрессионные модели, описывающие влияние величины уклона дороги и количества осадков на скорость автолесовоза. Указанные зависимости получены для различных категорий дорог и периодов года при движении в порожнем и грузовом направлениях. Все уравнения имеют достаточно высокую точность и являются статистически значимыми. Построенные зависимости проиллюстрированы графически. Полученные результаты могут быть использованы при планировании развития сети дорог на лесной территории, выборе способов, методов и объемов вывозки древесины. Данное исследование в целом представляет результаты, систематизирующие накопленные к настоящему времени знания по исследуемым вопросам, а также предлагает ряд новых подходов к оценке скорости лесовозных дорог.

Ключевые слова: скорость автолесовоза, величина уклона, количество осадков, регрессионная модель, климатические условия, лесовозная дорога

\title{
INVESTIGATION OF THE DEPENDENCE OF THE SPEED OF LOGGING TRUCKS ON NATURAL AND CLIMATIC FACTORS \\ ${ }^{1}$ Mokhirev A.P., ${ }^{2}$ Rukomoynikov K.P., ${ }^{1}$ Gerasimova M.M., ${ }^{1}$ Medvedev S.O. \\ ${ }^{1}$ Lesosibirsk Branch of Reshetnev Siberian State University of Science and Technology, Lesosibirsk,e-mail: ale-mokhirev@yandex.ru; \\ ${ }^{2}$ Volga State University of Technology, Yoshkar-Ola, e-mail: rukomojnikovkp@volgatech.net
}

The availability of forest resources is a major factor in the development of logging infrastructure. When determining it, the maximum possible volume of wood removal is calculated, depending on the capacity of transport routes, which is affected by a variety of production and climatic factors. One of the parameters that allows you to predict the capacity of forest roads is the speed of the logging truck. It can act as an indicator of the road condition and be used as an optimality criterion for optimizing forest transport processes in the development of woodlands. This article is devoted to the study of the dependence of this indicator on natural and climatic factors when driving on various categories of logging roads (highway, branch, us) at different times of the year. The object of research is automobile logging roads located in intensively used logging areas of the Krasnoyarsk territory. To obtain regression equations, the experiment was planned. Regression models were found that describe the influence of road slope and precipitation on the speed of a logging truck. These dependencies are obtained for different categories of roads and periods of the year when driving in empty and cargo directions. All equations have a fairly high accuracy and are statistically significant. The constructed dependencies are graphically illustrated. The results obtained can be used in planning the development of a road network in the forest area, selecting methods, methods and volumes of wood removal. This study generally presents results that systematize the knowledge accumulated to date on the issues under study, as well as offers a number of new approaches to assessing the speed of logging roads.

Keyword: logging truck speed, slope, precipitation, regression model, climate conditions, logging road

При определении доступности лесных ресурсов важным элементом является расчет максимально возможного объема вывозки древесины при определенных природно-климатических и производственных условиях.

Пропускная способность транспортных путей зависит от большого числа факторов: дорожных условий (ширины проезжей части, продольного уклона, радиуса кривых в плане, расстояния видимости и др.), состава потока автомобилей, наличия средств регулирования, погодно-климатических условий, возможности маневрирования автомобилей по ширине проезжей части, психофизиологических особенностей во- 
дителей и конструкции автомобилей $[1 ; 2]$. Анализируя представленную информацию, можно разделить факторы на управляемые, связанные с человеком (состояние дорожного покрытия, геометрические параметры дороги, пересечения и примыкания дорог) и неуправляемые природно-климатические факторы.

Чем выше категория дороги, интенсивность и скорость движения, тем менее ощутимо влияние природно-климатических факторов на режим движения. Из их числа наибольшее влияние имеют осадки разного вида, уклон транспортного пути, дальность видимости и скорость ветра. При этом на различных категориях лесовозных дорог (магистраль, ветка, ус) в различное время года они имеют разное значение.

Разработка математических зависимостей для расчета скорости лесовозного транспорта является актуальной задачей. На сегодняшний день опубликованы труды многих ученых, посвященные данному вопросу. В работах [3-5] приведены расчетные зависимости для определения скорости лесовозного автопоезда во всех режимах движения с учетом всех основных факторов, влияющих на показатели движения. Объектом исследований [6; 7] являются характеристики автомобильных дорог, по которым производится вывозка лесоматериалов. Авторы используют практические наблюдения за отдельными участками дороги для выявления закономерностей в изменении скоростных режимов движущихся транспортных средств. В работе [8] приведены математические зависимости, описывающие влияние климатических факторов на скорость разных групп лесовозов. Однако в данном исследовании не отражена зависимость от такого фактора, как рельеф местности, который оказывает значительное влияние на указанный показатель.

Целью данных исследований является нахождение зависимости скорости движения автолесовозов от таких природно-климатических факторов, как величина уклона транспортного пути и количество осадков при движении на различных категориях лесовозных дорог (магистраль, ветка, ус) в различное время года.

\section{Материалы и методы исследования}

Объектом исследования выступили автомобильные лесовозные дороги, находящиеся в интенсивно используемых лесозаготовительных районах Красноярского края (Енисейский, Мотыгинский). В ходе иссле- дования использованы данные о скорости движения автолесовозов при вывозке древесины с лесной территории на береговые нижние склады во время лесозаготовительного сезона 2019-2020 гг. Анализировались сведения о природно-климатических факторах за аналогичные периоды времени, находящиеся в архивных сведениях о погоде на электронном ресурсе rp5.ru по соответствующим метеорологическим постам (Енисейский, Мотыгинский).

Вследствие неоднородности природно-климатических и производственных условий в различные временные интервалы, a также возможности их классификации по наиболее близким характеристикам, весь лесозаготовительный процесс разделен на пять периодов [9]: зимний, зимне-весенний, весенний, летний, осенний. Однако зимне-весенний и осенний периоды приходятся на распутицу, при которой вывозка не производится, поэтому они не анализировались.

Кроме климатических факторов, на скорость вывозки влияют и производственные. Наиболее значимые - тип автомобильной дороги (магистраль, ветка, ус) и направление движения (грузовое, порожнее). Для каждого из этих условий строится своя зависимость.

Для выявления зависимости скорости автолесовоза на магистрали от всех рассматриваемых факторов, а также межфакторной зависимости выполнено 75 наблюдений, заключающихся в измерениях скорости лесовоза на магистрали, величины уклона, количества осадков, дальности видимости, скорости ветра. Исследования проводились при прочих равных условиях: участок без поворотов более 300 м, анализируемый уклон \pm 20 более 300 м. При этом достигается равномерная скорость без влияния данных факторов.

Для проведения эксперимента собрана информация, полученная из следующих ресурсов: сводный отчет перемещения (положения) автолесовоза по маршруту его движения, сгенерированный из ГЛОНАССисточника в табличный редактор Microsoft Excel; Google-карты; программа Google Earth Pro; архив метеоданных в Красноярском крае с сайта расписания погоды rp5.ru.

Анализировались маршруты автолесовоза в грузовом и порожнем направлениях. Учитывались величина уклона, тип дороги, количество осадков, дальность видимости, скорость ветра и фиксировалась скорость лесовоза при соответствующих значениях факторов. 
Для построения регрессионной зависимости скорости автолесовоза от рассмотренных факторов введены обозначения: $y$ - исследуемый выходной параметр (скорость), факторы: $x_{1}-$ величина уклона, $x_{2}-$ количество осадков, $x_{3}$ - дальность видимости, $x_{4}$ - скорость ветра.

На основании полученных значений коэффициентов парной корреляции сделан вывод о существенной зависимости между факторами $x_{2}$ и $x_{3}, x_{3}$ и $x_{4}$ (коэффициенты корреляции $\left.r_{x_{2} x_{3}}=-0,67, \quad r_{x_{3} x_{4}}=-0,68\right)$ и слабом влиянии фактора $x_{4}$ на выходной параметр $\left(r_{y x_{4}}=-0,16\right)$. Поэтому факторы $x_{3}$ и $x_{4}$ исключены из рассмотрения. Таким образом, для исследования зависимости скорости движения автолесовозов от природно-климатических факторов рассматриваются показатели: величина уклона дороги с учетом подъема или спуска и количество осадков.

Для сбора данных выполнено планирование пассивного эксперимента, в котором при различных условиях фиксировалась скорость движения автолесовоза.

В условиях каждого из опытов для трех типов дороги: магистрали, ветки, уса - выполнены в зимнем, весеннем и летнем периодах предварительно по 5 замеров скорости лесовоза, уклона дороги. Количество осадков получено на основании данных, приведенных на сайте rp5.ru. Результаты наблюдений для каждого опыта статистически обработаны: вычислены среднее значение выходного параметра, дисперсия, среднее квадратическое отклонение, коэффициент вариации. На основании полученных результатов определено необходимое число наблюдений в каждом опыте при точности вычисления среднего значения выходного параметра, равной $5 \%$.

Обработка статистических данных, полученных в соответствии с найденными объемами выборок, осуществлялась с применением системы Statistica. Моделирование осуществлялось методом наименьших квадратов, оценки параметров моделей регрессии определялись методом Левенберга-Марквардта.

\section{Результаты исследования и их обсуждение}

Регрессионные модели, отражающие зависимость скорости автолесовоза от величины уклона и количества осадков, для трех типов дорог (магистраль, ветка, ус) при движении в грузовом и порожнем направлениях представлены в таблице. Най- денные значения коэффициента (индекса) детерминации $\left(R^{2}\right)$ свидетельствуют о достаточно высокой точности полученных уравнений [10].

Проверка с помощью $t$-критерия Стьюдента гипотезы о статистической незначимости параметров уравнений позволила с вероятностью 95\% сделать вывод о том, что они являются статистически значимыми.

Оценивая полученные зависимости, представленные графически (рис. 1-3), можно сделать следующие выводы. 1. Скорости лесовозов существенно снижаются при изменении величины уклона (как в большую, так и меньшую сторону) в зимний период. В порожнем направлении зависимость от осадков существенно выше. В то время как при наличии грузов в лесовозе зависимость от осадков сглаживается. 2. В весенний период влияние осадков на скорость лесовозов существенно выше. Данный факт обусловлен техническими и психологическими особенностями управления лесовозной техникой в сложных погодных условиях. Зависимость от уклона идентична зимнему периоду времени. Аналогично происходит и сглаживание влияния количества осадков в груженом варианте движения лесовозной техники.

Отличные модели от предыдущих характерны для летнего периода времени. В данном случае для магистрали и ветки скорость увеличивается с уменьшением величины уклона. При этом отрицательный уклон приводит к еще большему приросту скорости. Исключение составляет движение по усам, где малые скорости и качество дорог практически не позволяют увеличивать скорость при отрицательном уклоне, а сама скорость достаточно стабильна и неизменчива. Количество осадков при порожнем движении по магистралям и веткам, а также по магистралям в груженом варианте практически не оказывает влияния на скорость. При этом при движении по усам и в груженом состоянии по веткам влияние осадков на скорость существенно.

Полученные регрессионные модели могут быть использованы при имитационном моделировании технологического процесса вывозки древесины на нижний склад лесозаготовительных предприятий Красноярского края. При практическом применении данных зависимостей возможно оптимизировать технологический процесс работы лесозаготовительных машин в определенных природно-производственных условиях [11-13]. 
Регрессионные модели

\begin{tabular}{|c|c|c|c|c|c|}
\hline № & Период & Тип дороги & $\begin{array}{l}\text { Направление } \\
\text { движения }\end{array}$ & Регрессионная модель & $R^{2}$ \\
\hline 1 & \multirow{6}{*}{ зимний } & \multirow{2}{*}{ магистраль } & порожнее & $y=54,419+0,13 x_{1}-1,408 x_{2}-0,275 x_{1}^{2}$ & 0,72 \\
\hline 2 & & & грузовое & $y=40,807-0,351 x_{1}-0,864 x_{2}-0,186 x_{1}^{2}$ & 0,74 \\
\hline 3 & & \multirow{2}{*}{ ветка } & порожнее & $y=34,544-0,256 x_{1}-1,318 x_{2}-0,113 x_{1}^{2}$ & 0,74 \\
\hline 4 & & & грузовое & $y=24,814-0,227 x_{1}-0,406 x_{2}-0,128 x_{1}^{2}$ & 0,77 \\
\hline 5 & & \multirow{2}{*}{$\mathrm{yc}$} & порожнее & $y=22,036-0,301 x_{1}-0,487 x_{2}-0,078 x_{1}^{2}$ & 0,75 \\
\hline 6 & & & грузовое & $y=14,53-0,168 x_{1}-0,142 x_{2}-0,048 x_{1}^{2}$ & 0,71 \\
\hline 7 & \multirow{6}{*}{ весенний } & \multirow{2}{*}{ магистраль } & порожнее & $y=49,041+0,292 x_{1}-1,758 x_{2}-0,118 x_{1}^{2}$ & 0,73 \\
\hline 8 & & & грузовое & $y=39,101+0,663 x_{1}-0,75 x_{2}-0,231 x_{1}^{2}$ & 0,8 \\
\hline 9 & & \multirow{2}{*}{ ветка } & порожнее & $y=43,085+0,301 x_{1}-1,101 x_{2}-0,166 x_{1}^{2}$ & 0,81 \\
\hline 10 & & & грузовое & $y=34,965+0,713 x_{1}-1,254 x_{2}-0,165 x_{1}^{2}$ & 0,9 \\
\hline 11 & & \multirow{2}{*}{ yc } & порожнее & $y=19,28-0,028 x_{1}-0,984 x_{2}-0,048 x_{1}^{2}$ & 0,73 \\
\hline 12 & & & грузовое & $y=13,851-0,058 x_{1}-0,633 x_{2}-0,04 x_{1}^{2}$ & 0,72 \\
\hline 13 & \multirow{6}{*}{ летний } & \multirow{2}{*}{ магистраль } & порожнее & $y=42,572-1,479 x_{1}+0,361 x_{2}-0,035 x_{1}^{2}$ & 0,81 \\
\hline 14 & & & грузовое & $y=43,535-1,566 x_{1}+0,331 x_{2}-0,147 x_{1}^{2}$ & 0,84 \\
\hline 15 & & \multirow{2}{*}{ ветка } & порожнее & $y=38,31-1,566 x_{1}-1,703 x_{2}-0,033 x_{1}^{2}$ & 0,85 \\
\hline 16 & & & грузовое & $y=37,008-0,934 x_{1}-4,235 x_{2}-0,031 x_{1}^{2}$ & 0,71 \\
\hline 17 & & \multirow{2}{*}{ yc } & порожнее & $y=26,04-0,092 x_{1}-2,567 x_{2}-0,068 x_{1}^{2}$ & 0,7 \\
\hline 18 & & & грузовое & $y=19,955-0,177 x_{1}-2,958 x_{2}-0,023 x_{1}^{2}$ & 0,85 \\
\hline
\end{tabular}

\section{Заключение}

Данное исследование в целом представляет результаты, систематизирующие накопленные к настоящему времени знания по исследуемым вопросам, а также предлагает ряд новых подходов к оценке скорости лесовозных дорог.

Получены зависимости скорости лесовозной техники от количества осадков и величины уклона местности. Показано, что как осадки, так и рельеф в значительной мере сказываются на скорости техники, а значит эффективности вывозки древесины с лесной территории. Получены результаты для порожнего и грузового направлений, а также для магистралей, веток и усов. Такое разнообразие результатов позволяет получить целостную картину движения лесовозной техники на всем лесозаготовительном периоде и формировать планы деятельности предприятий. 


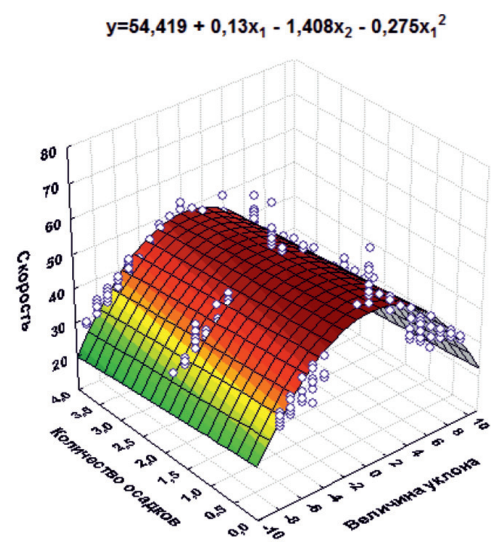

a)

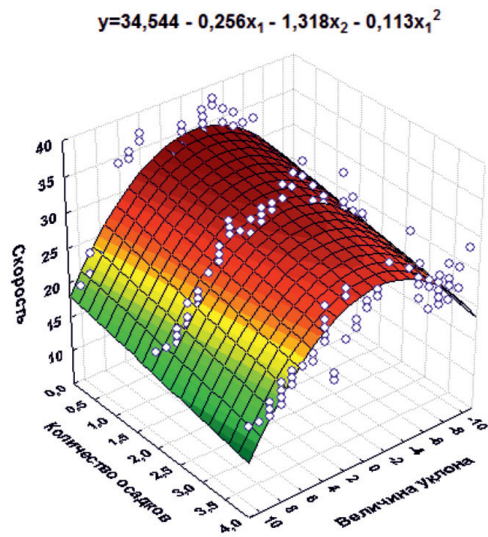

B)

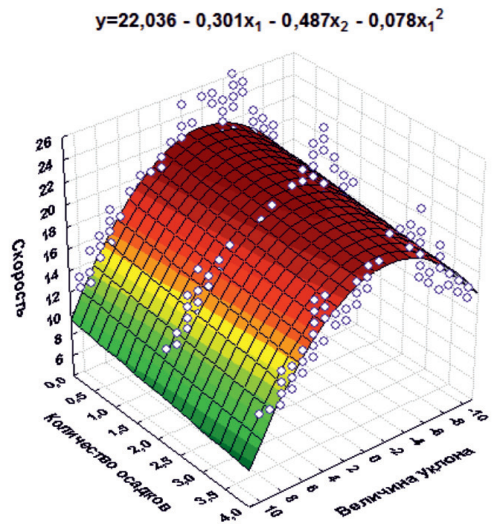

d) $y=40,807-0,351 x_{1}-0,864 x_{2}-0,186 x_{1}{ }^{2}$

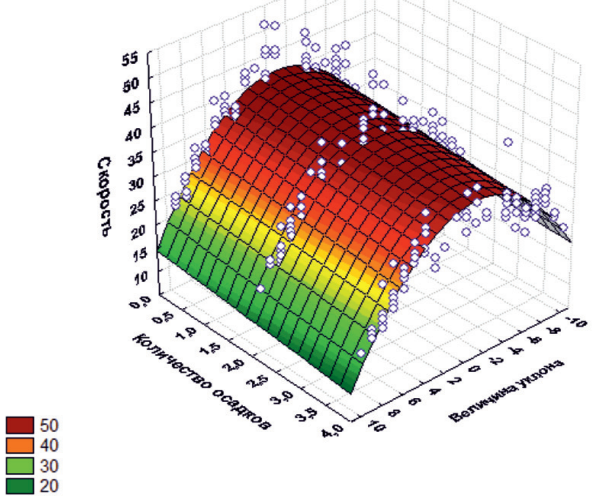

б)

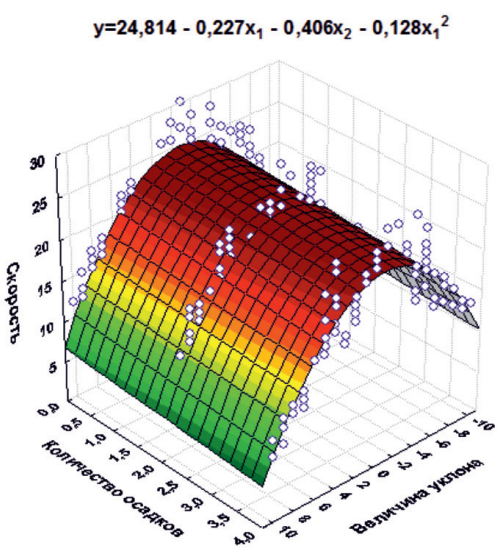

2)

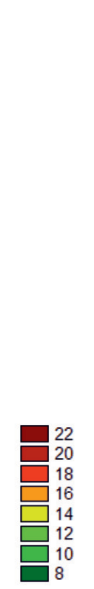

$y=14,53-0,168 x_{1}-0,142 x_{2}-0,048 x_{1}{ }^{2}$

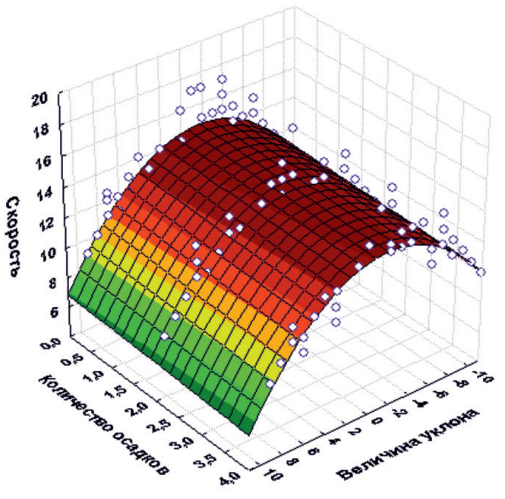

e)

Рис. 1. Зависимость скорости лесовоза от величины уклона и количества осадков в зимнем периоде: $а$ - на магистрали в порожнем направлении; б - на магистрали в грузовом направлении; в - на ветке в порожнем направлении; г - на ветке в грузовом направлении; $\partial$ - на усах в порожнем направлении; $e$ - на усах в грузовом направлении 


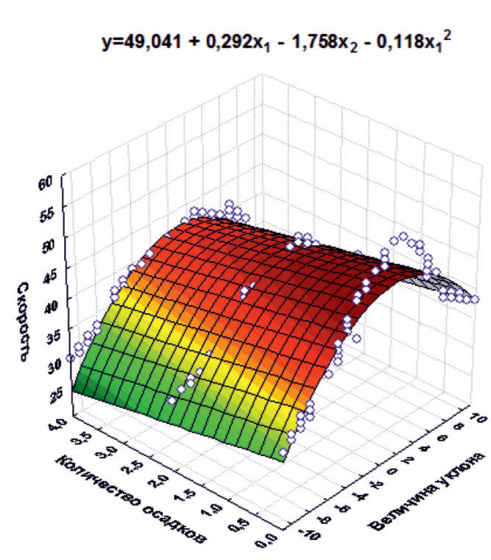

a)

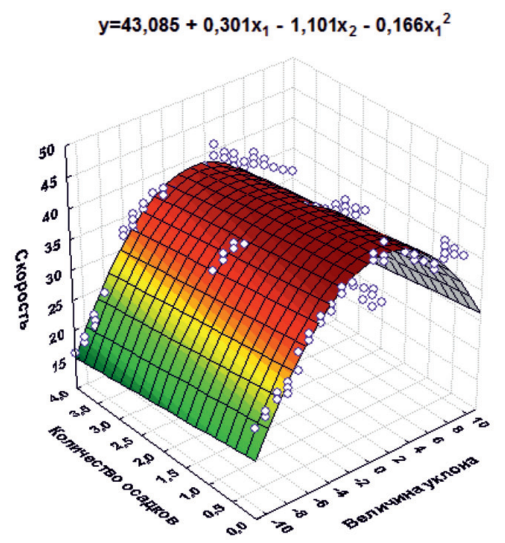

6)

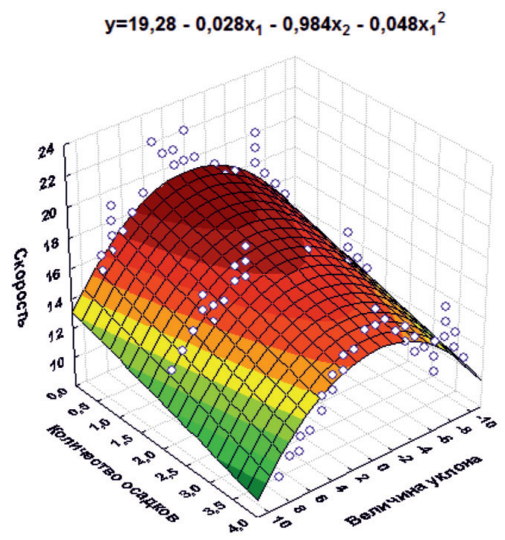

d)
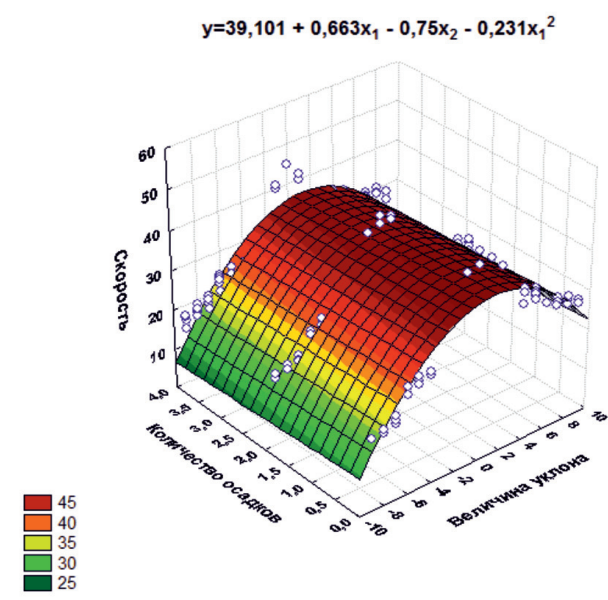

б)

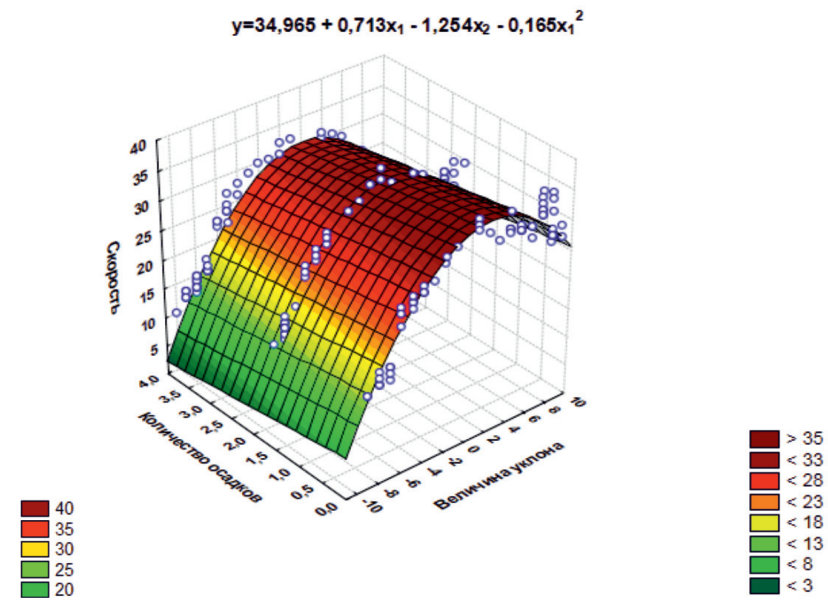

2)

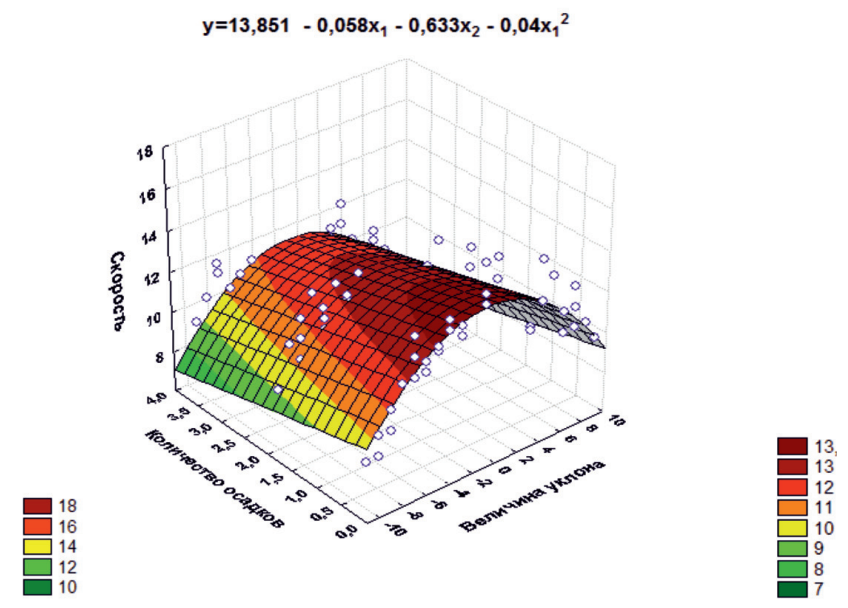

e)

Рис. 2. Зависимость скорости лесовоза от величины уклона и количества осадков в весеннем периоде: а - на магистрали в порожнем направлении; б - на магистрали в грузовом направлении; в - на ветке в порожнем направлении; г - на ветке в грузовом направлении; $\partial$ - на усах в порожнем направлении; $e$ - на усах в грузовом направлении 


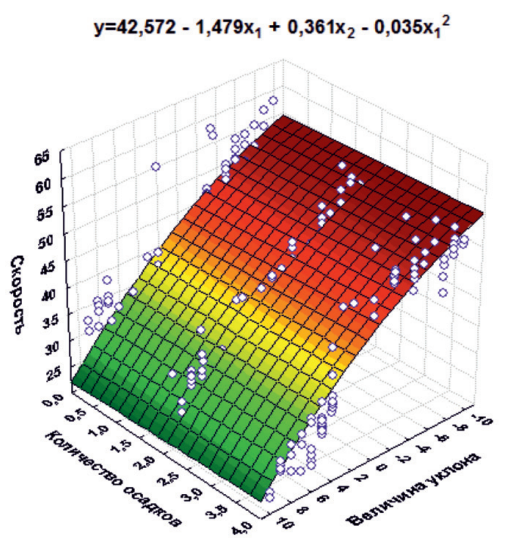

a)

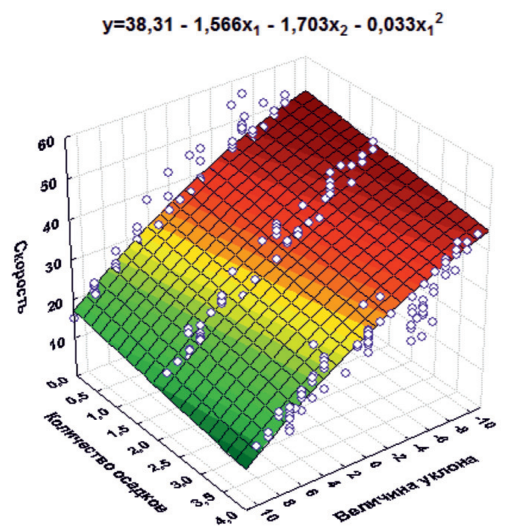

6)

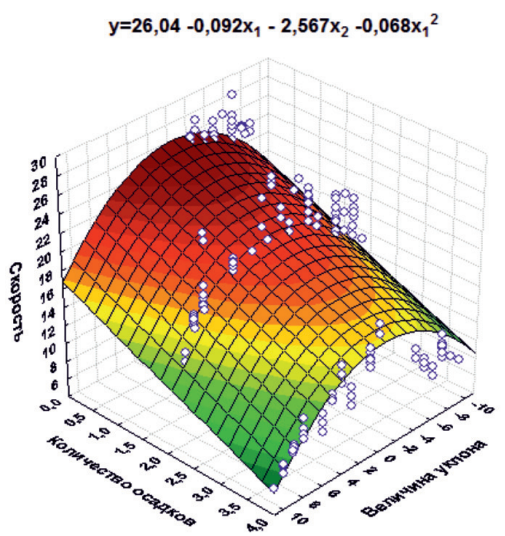

d)

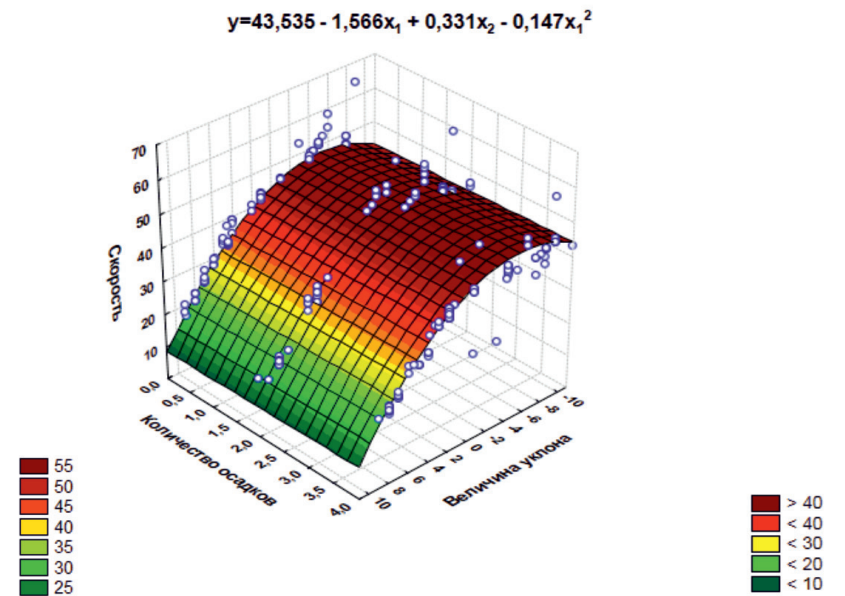

б)

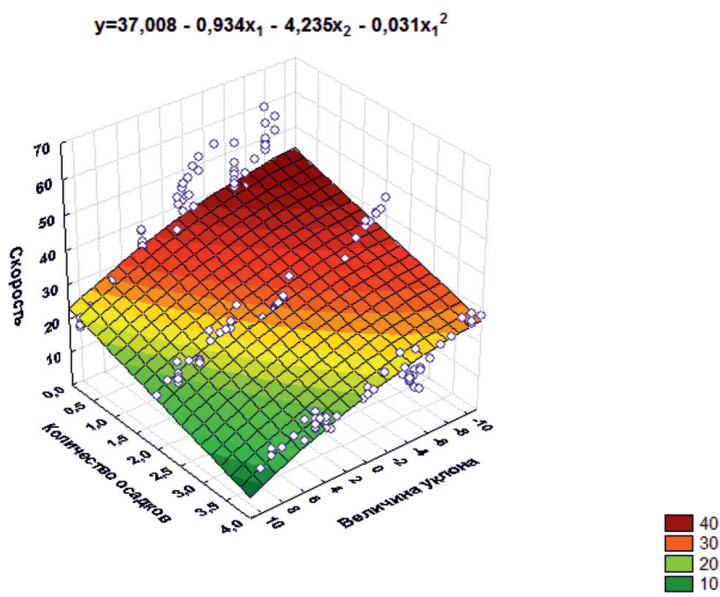

2)

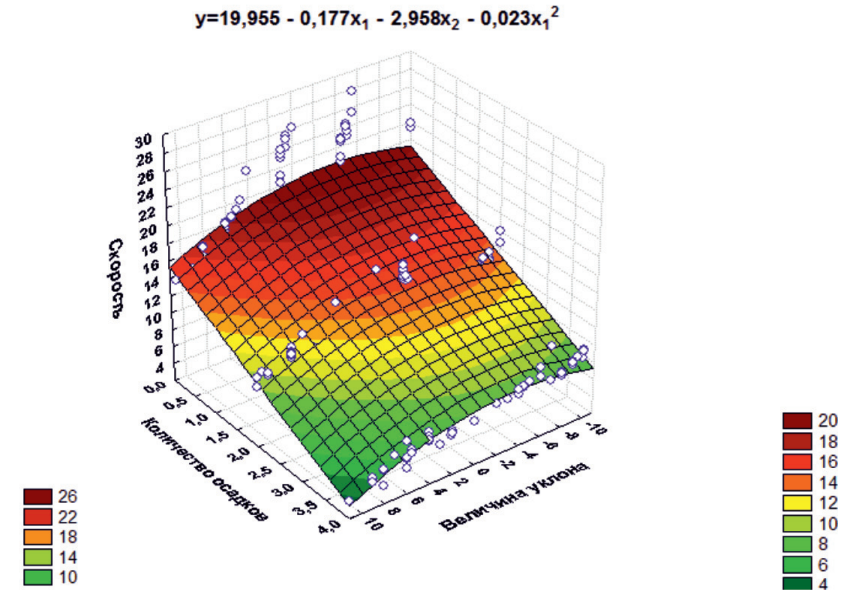

e)

Рис. 3. Зависимость скорости лесовоза от величины уклона и количества осадков в летнем периоде: а - на магистрали в порожнем направлении; б - на магистрали в грузовом направлении; в - на ветке в порожнем направлении; г - на ветке в грузовом направлении; $\partial$ - на усах в порожнем направлении; $е$ - на усах в грузовом направлении 
Полученные результаты могут быть использованы при планировании развития сети дорог на лесной территории, выбора способов и методов вывозки древесины.

Исследование выполнено при финансовой поддержке РФФИ, Правительства Красноярского края, Краевого фонда науки и ООО «Красресурс 24» в рамках научного проекта № 20-410-242901 и в рамках проекта «Разработка фундаментальныхх основ проектирования лесной инфраструктуры как динамически изменяемой системы в условиях деятельности лесозаготовительного производства» № 19-410-240005, поддержанного за счет средств иелевого финансирования, предоставленного РФФИ, Правительством Красноярского края и Краевым фондом науки.

\section{Список литературы / References}

1. Платонова Е.В. Обоснование пропускной способности лесовозных дорог при различных скоростных режимах и моделях транспортного потока: дис. ... канд. технич. наук. Архангельск, 2006. $151 \mathrm{c}$.

Platonova E.V. Substantiation of the throughput capacity of logging roads at various speed modes and models of transport flow: dis. ... каnd. tekhnich. nauk. Arkhangelsk, 2006. 151 p. (in Russian).

2. Мохирев А.П., Медведев С.О., Смолина О.Н. Факторы, влияющие на пропускную способность лесовозных дорог // Лесотехнический журнал. 2019. Т. 9. № 3 (35). С. $103-$ 113. DOI: $10.34220 /$ issn.2222-7962/2019.3/10.

Mokhirev A.P., Medvedev S.O., Smolina O.N. Factors affecting the capacity of logging roads // Lesotekhnicheskiy zhurnal. 2019. Vol. 9. № 3 (35). P. 103-113 (in Russian).

3. Скрыпник В.И., Кузнецов А.В., Баклагин В.Н. Анализ и расчет параметров движения лесовозных автопоездов // Труды лесоинженерного факультета ПетрГУ. 2010 № 8. C. 140-143.

Skrypnik V.I., Kuznetsov A.V., Baklagin V.N. Analysis and calculation of parameters of movement of logging trucks // Trudy lesoinzhenernogo fakul’teta PetrGU. 2010. № 8. P. 140 143 (in Russian).

4. Скрыпник В.И., Качанов А.Н. Новые методы тяговых расчетов на лесовозном транспорте. Петрозаводск, 1979. $118 \mathrm{c}$.

Skrypnik V.I., Kachanov A.N. New methods of traction calculations on timber transport. Petrozavodsk, 1979. 118 p. (in Russian).

5. Шегельман И.Р., Скрыпник В.И., Пладов А.В. Моделирование движения лесовозных автопоездов на ПВЭМ. Петрозаводск: Изд. ПетрГУ, 2003. 234 с.

Shegelman I.R., Skrypnik V.I., Pladov A.V. Modeling of the movement of logging trucks on the PVEM. Petrozavodsk: Izd. PetrGU, 2003. 234 p. (in Russian).

6. Сивков Е.Н., Скрыпников А.В., Чернышова Е.В Условия движения по лесовозным дорогам // Изучение лесосырьевой базы Республики Коми: научно-методический аспект: сборник материалов научно-практической конференции по научной теме института «Разработка научных ос- нов и практических рекомендаций по переводу лесосырьевой базы Республики Коми на инновационную интенсивную модель расширенного воспроизводства на 2015-2020 годы». Сыктывкар, 2017. C. 19-23.

Sivkov E.N., Skrypnikov A.V., Chernyshova E.V. Conditions of movement on timber roads // Study of the timber resource base of the Komi Republic: scientific and methodological aspect: collection of materials of the scientific and practical conference on the scientific topic of the institute «Development of scientific foundations and practical recommendations for transferring the timber resource base of the Komi Republic to an innovative intensive model of expanded reproduction for 20152020». Syktyvkar, 2017. P. 19-23 (in Russian).

7. Скрыпников А.В., Кондрашова Е.В., Скворцова Т.В., Дорохин С.В. Влияние условий движения на скоростные режимы транспортных потоков при вывозке древесины // Современные наукоемкие технологии. 2014. № 4. С. 153-153.

Skrypnikov A.V., Kondrashova E.V., Skvortsova T.V., Dorokhin S.V. Influence of traffic conditions on high-speed modes of transport flows during wood removal // Modern high technologies. 2014. № 4. Р. 153-153 (in Russian).

8. Коваленко Т.В., Коточигов М.В. Использование климатической информации для организации транспортного освоения лесных массивов // Технология и оборудование лесопромышленного комплекса: сборник научных трудов. Выпуск 6. СПб.: СПбГЛТУ, 2013. С. 104-108.

Kovalenko T. Kotochigov M.V. Use of climate information for the organization of transport development of woodlands // Technology and equipment of the forest industry complex: collection of scientific papers. Issue 6. SPb.: SPbGLTU, 2013. P. 104-108 (in Russian).

9. Мохирев А.П., Мохирев П.Ф. Исследование специфики лесозаготовок в Красноярском крае // Resources and Technology. 2015. T. 12. № 2. C. 98-108. DOI: 10.15393/ j2.art.2015.3061.

Mokhirev A.P., Mokhirev P.F. Study of the specifics of logging in Krasnoyarsk region // Resources and Technology. 2015. Vol. 12. № 2. P. 98-108 (in Russian).

10. Mazurkin P.M. Method of identification. International Multidisciplinary Scientific Geo Conference Surveying Geology and Mining Ecology Management, SGEM 14. 2014. P. $427-434$.

11. Шегельман И.Р., Скрыпник В.И., А.В. Кузнецов. Анализ показателей работы и оценка эффективности лесозаготовительных машин в различных природно-производственных условиях // Ученые записки Петрозаводского государственного университета. 2010. № 4. C. 66-75.

Shegelman I.R., Skrypnik V.I., Kuznetsov A.V. Analysis of performance indicators and evaluation of efficiency of logging machines in various natural production conditions // Uchenyye zapiski Petrozavodskogo gosudarstvennogo universiteta. 2010. № 4. P. 66-75 (in Russian).

12. Мохирев А.П. Методика выбора лесозаготовительных машин под природно-климатические условия // Лесотехнический журнал. 2016. Т. 6. № 4 (24). С. 208-215. DOI: $10.12737 / 23459$.

Mokhirev A.P. Method of selecting logging machines for natural and climatic conditions // Lesotekhnicheskiy zhurnal. 2016. Vol. 6. № 4 (24). P. 208-215 (in Russian).

13. Grigorev I.V., Khitrov E.G., Kalistratov A.V., Stepanishcheva M.V. Dependence of filtration coefficient of forest soils to its density. Proceedings of the 14th International Multidisciplinary Scientific Geoconferences, Vol. 2 «Water Resources. Marine and Ocean Ecosystems», 16-26 June 2014, Albena, Bulgaria, 2014. P. 339-344. 